\title{
Copper Extraction from Waste Printed Circuit Boards
}

\author{
Chaverra Dairo and Restrepo Oscar \\ School of Mines, Universidad Nacional de Colombia, Medellín 050034, Colombia
}

Received: August 11, 2014 / Accepted: August 21, 2014 / Published: August 25, 2014.

\begin{abstract}
The quick development in the electronics industry has allowed an increase in e-waste generation; which cannot be disposed of a traditional way due mainly to the content of hazardous and polluting elements. This has given rise to a social and environmental problem in terms of handling and end disposal. Further, these wastes have become a source of heavy metals, posing challenges for recovering them and development of efficient and environmentally responsible extraction methods. An extraction process to copper extraction from printed circuit boards has been proposed. This method consists on a size reduction, concentration by magnetic and electrostatic separation, leaching of copper in sulfuric acid solution with hydrogen peroxide and oxygen and electrowinning and copper oxychloride precipitation. Concentrates with up to 63\% copper and $85 \%$ maximum recovery were obtained. Copper extraction over $95 \%$ in $100 \mathrm{~mL}$ of $2.3 \mathrm{M}$ sulfuric acid solution with $18 \mathrm{~mL}$ of hydrogen peroxide during $60 \mathrm{~min}$ of process was achieved. Metallic copper with purity over $99 \%$ and copper oxychloride as a value-added product also were obtained. This process represents a viable alternative for the recovery of copper from e-waste, contributing to management and end disposal problems, closure of the metals cycle and global sustainable development.
\end{abstract}

Key words: Electronic waste, copper recycling, copper oxychloride, solid waste management, sustainable development.

\section{Introduction}

Electrical and electronic equipment (EEE), especially those related to telecommunications and information technology, have presented a quick development in recent decades and its usage time is reduced increasingly [1], proportionally, increased the amount of EEE that are discarded in the world. Thus the flow of waste electrical and electronic equipment (WEEE) is growing, being the components of waste faster growth. Between 20 and 50 million tons are annually generated in the world, with an annual increase of $3 \%-5 \%$ [2]. The enormous volume of WEEE generated today is an emerging environmental problem and a challenge in terms of storage/disposal and solid waste management [3]. First, they content hazardous elements [4], and second, it is not possible to dispose them in the traditional way. Due to simple handwork for metal extraction, large amounts of

Corresponding author: Dairo Chaverra, M.Sc., research field: extractive metallurgy. E-mail: dechaverraa@unal.edu.co. poisonous gas are released, and wastewater containing toxic substances is discharged into environment [5]. Improper disposal of WEEE can create both health and environmental hazards [6]. They are even considered as "the largest toxic waste problem of the century XXI” [7].

The printed circuit boards (PCB) are the base of the electronics industry, being an essential part of almost all EEE [8]. The PCB contain up to $20 \%$ by weight of $\mathrm{Cu}$ [2]. Given its varied metallic composition, various methods have been proposed for the recovery of different metals. Mechanical processes are usually used as a pretreatment step previous to the application of metallurgical techniques, which consist on dismantling, removal of hazardous elements, size reduction and concentration of the metal fraction. These processes are performed in order to release the metal bonded or encapsulated with resin and ceramics. Physical methods such as magnetic and electrostatic separation, flotation, pneumatic separation, have been studied for concentration [9-11]. 
PCBs are also processed by incineration and smelting that allows effective recovery of copper and an amount of precious metals. However, the process has the disadvantages of producing some contaminants and a slag with a complex metal content which presents complications for the final extraction [12]. In this process, the copper is oxidized, which facilitates subsequent dissolution in non-oxidizing acid environments.

Recent researches study the extraction of metals from PCB through bioleaching processes, especially for gold and copper [13, 14]. Copper extractions of the $93 \%, 86 \%$ and $100 \%$ are achieved $[15,16]$, in different microbial environments and times of process to 280 days.

Hydrometallurgical process are a promising option for use in the treatment of waste PCB. Compared to pyrometallurgy, hydrometallurgical processes offer relatively low capital cost and are particularly suitable for small-scale installations. An added advantage is flexibility, offering a possibility for selective extraction of base and precious metals of interest in waste PCB [2]. As the metals present in the waste PCB are in elemental form or in alloys, it is necessary an oxidative leaching process for the effective extraction of the metals of interest. Leaching techniques of precious metals consist of processes using cyanide, halides, thiourea and thiosulfate [17]. Different processes have been studied in aqueous solution using sulfuric acid [18] and hydrogen peroxide as oxidant [8, 19, 20], chlorine [21, 22], nitric acid and solvent extraction [12, 23], solutions of ammonium sulfate, ammonium [24, 25], by mediated electrochemical oxidation [26, 27], 1-butyl-3-methyl-imidazolium hydrogen sulfate ([bmim] $\mathrm{HSO}_{4}$ ) [28], for the extraction of copper. These processes studied have disadvantages in terms of recovery and some use unsuitable reagents for scaling at the industrial level.

The development and implementation of a process for recovering copper and/or byproducts of copper from electronic waste are presented in this paper. It was performed using physical processes together with chemical techniques used in extractive metallurgy. The process was proposed as a viable option for copper recovery from WEEE.

\section{Materials and Experiments}

The process shown in the flowchart of Fig. 1 was developed for copper extraction from electronic waste with a minimum emission of pollutants species.

4,300 g of printed circuit boards of different types and trademark, as a representative sample, were processed. At each stage of the process three samples were taken for chemical analysis. Samples were dissolved in aqua regia with a subsequent filtration process. The copper content in the solution was measured by atomic adsorption equipment with the AA Spectrometer iCE 300 Series Thermo Scientific.

Manual size reduction using a cutter for cutting of metal sheets to obtain maximum particle size $2 \mathrm{~cm}$ was made. Then, the material was passed once for a pulverizer Braun Direct Driven Pulverizer UD32, which works at $400 \mathrm{rpm}$. The material was reduced in size in the pulverizer by abrasion due to friction between the particles themselves and the plates of the pulverizer. The aim was to obtain a maximum particle size of $2 \mathrm{~mm}$ to achieve release of $99 \%$ of copper according Zhang and Forssberg [29].

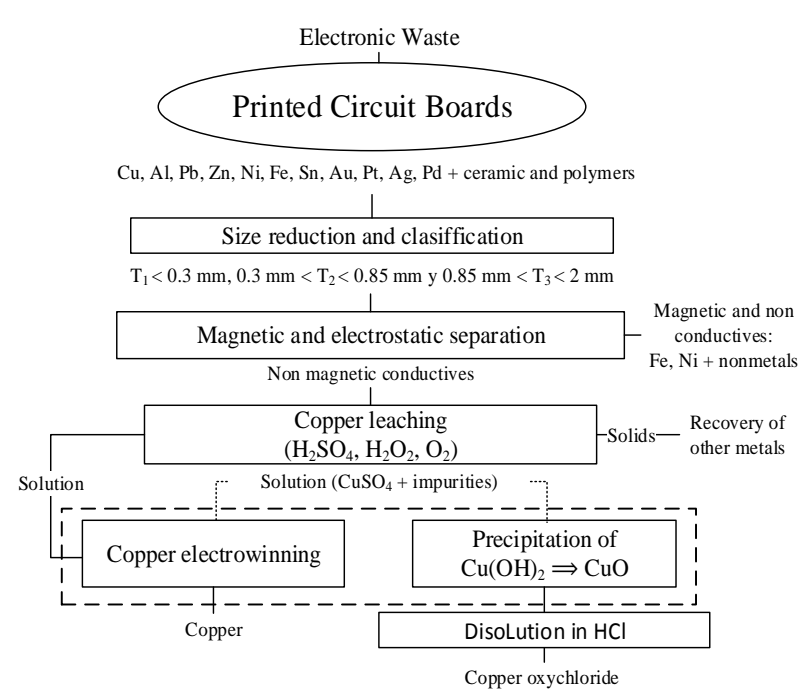

Fig. 1 Process flowchart. 
The material was classified into three particle sizes: $\mathrm{T}_{1}<0.3 \mathrm{~mm}, 0.3 \mathrm{~mm}<\mathrm{T}_{2}<0.85 \mathrm{~mm}$ and $0.85 \mathrm{~mm}<\mathrm{T}_{3}$ $<2 \mathrm{~mm}$. Size grading was carried out using sieves of the series ASTM-E-11 by Ro-Tap. A concentration process was performed by magnetic and electrostatic separation to remove some species of little importance and obtain a suitable material for good extractive metallurgical process. Each size fraction was processed in the magnetic separator, yielding a stream of magnetic and other of non-magnetic materials. The non-magnetic stream was subsequently processed on the electrostatic separator. Non-conductive and other conductive material fractions were obtained. The fraction conductive material, enriched in metals, corresponds to final concentrate.

To test the magnetic separator Carpco Model MIH(13)111-5 Laboratory High-Intensity Induced-Roll Magnetic Separator was used operated at a roll speed between $120 \mathrm{rpm}$ and $125 \mathrm{rpm}$ and vibration control in 50 units, with a current of 1.0 A. A Carpco Laboratory Electrostatic High-Tension Separator was used in the electrostatic separation with an intensity of $20 \mathrm{kV} \mathrm{DC,} 10 \mathrm{kV}$ DC and roll rotation speed of $50 \mathrm{rpm}$.

\subsection{Copper Leaching}

Copper leaching in aqueous sulfuric acid with hydrogen peroxide as oxidizing agent, by magnetic stirring at room temperature and atmospheric pressure was studied. The $0.3 \mathrm{~mm}<\mathrm{C}_{2}<0.85 \mathrm{~mm}$ fraction of the concentrate obtained was taken.

A sequential experimentation starting with a completely randomized $2^{4-1}$ fractional factorial design with 4 replicates at the center, and subsequent central composite design, were made in order to determine operating conditions. The effect of the concentration of sulfuric acid (A), volume of hydrogen peroxide added to the solution (B) amount of solids (C) and agitation speed (D) was studied. The response variable $(Y)$ for the experiment was the percentage of copper extraction.
An amount of solids of $4 \mathrm{~g}$ and $8 \mathrm{~g}$, which is equivalent to $40 \mathrm{~kg} / \mathrm{m}^{3}$ and $80 \mathrm{~kg} / \mathrm{m}^{3}$ was initially studied. The factors and levels studied in the leaching process are summarized in Table 1 and the design matrix is shown in the Table 2. Experimental tests were performed in a solution of $100 \mathrm{~mL}$ in a glass beaker of $250 \mathrm{~mL}$ capacity on a RCT basic Ikamag ${ }^{\circledR}$ Safety control magnetic stir plate during a time of $60 \mathrm{~min}$. The design and analysis of experiments were performed with the help of the Minitab ${ }^{\circledR} 16$ software.

Copper extraction for each experimental test was calculated taking into account the copper content in the solid sample and the amount of copper in the solution according to the Eq. (1).

Extraction $(\%)=\frac{\text { Copper in solution }}{\text { Copper in the solid sample }} * 100$

The amount of copper in solution was measured by complexometric titration using Titriplex® III $0.01 \mathrm{M}$.

\subsection{Obtaining Copper and Copper Oxychloride}

Copper oxide (II) (CuO) was precipitated from the copper sulphate solution by adding sodium hydroxide

Table 1 Factors and levels of the experimental design.

\begin{tabular}{llll}
\hline \multirow{2}{*}{ Factors } & \multicolumn{3}{c}{ Levels } \\
\cline { 2 - 4 } & Low & Base & High \\
\hline A: Sulfuric acid concentration (M) & 1 & 1.5 & 2 \\
B: Hydrogen peroxide added (mL/100 mL) & 5 & 10 & 15 \\
C: Solids (g/100 mL) & 4 & 6 & 8 \\
D: Agitation speed (rpm) & 350 & 400 & 450 \\
\hline
\end{tabular}

Table 2 Experimental results.

\begin{tabular}{llllll}
\hline \# test & A & B & C & D & Extraction (\%) \\
\hline 1 & 1 & 5 & 4 & 350 & 45.67 \\
2 & 2 & 15 & 8 & 450 & 77.96 \\
3 & 1.5 & 10 & 6 & 400 & 69.30 \\
4 & 1 & 15 & 4 & 450 & 87.88 \\
5 & 1.5 & 10 & 6 & 400 & 67.20 \\
6 & 1 & 5 & 8 & 450 & 29.92 \\
7 & 1.5 & 10 & 6 & 400 & 69.30 \\
8 & 1 & 15 & 8 & 350 & 68.98 \\
9 & 2 & 15 & 4 & 350 & 94.49 \\
10 & 2 & 5 & 8 & 350 & 37.33 \\
11 & 1.5 & 10 & 6 & 400 & 69.09 \\
12 & 2 & 5 & 4 & 450 & 66.46 \\
\hline
\end{tabular}


and with subsequent heating to a maximum temperature of $90{ }^{\circ} \mathrm{C}$. The precipitate was filtered and dried at room temperature. The $\mathrm{CuO}$ was dissolved in $1 \mathrm{M}$ hydrochloric acid solution at room temperature. The solution of $\mathrm{CuCl}_{2}$ obtained was neutralized by adding sodium hydroxide in order to obtain a precipitate of copper oxychloride.

For the electrowinning process, an electrolysis cell, with acrylic and capacity of $270 \mathrm{~cm}^{3}$ was constructed. A steel plate 304 with a total area of $36 \mathrm{~cm}^{2}$ was used as the cathode. Lead plates were used for the anodes. For this process, the richest copper solutions obtained in the leaching tests were taken. The test was performed with a fixed current density of $250 \mathrm{~A} / \mathrm{m}^{2}$ supplied by a BK PRECISION High Current DC Regulated Power Supply Model 1796.

\section{Results}

The results obtained in the concentration process by means of magnetic and electrostatic separation are summarized in the Fig. 2. It also shows the copper content in each of the three particle size fractions. An initial concentration of copper of $23.15 \%$ in the fraction less than $2 \mathrm{~mm}$ was calculated.

As a result of magnetic and electrostatic separation, three copper concentrates of $44 \%, 63 \%$ and $58 \%$ for $\mathrm{T}_{1}$, $\mathrm{T}_{2}$ and $\mathrm{T}_{3}$ fractions respectively were obtained. It is possible to work with two different size fractions, a size fraction less than $0.3 \mathrm{~mm}$ and a size fraction greater than $0.3 \mathrm{~mm}$ and less than $2 \mathrm{~mm}$. The copper recovery was $63 \%, 73 \%$ and $85 \%$ for size fractions $\mathrm{T}_{1}, \mathrm{~T}_{2}$ and $\mathrm{T}_{3}$, respectively, which shows that the concentration for magnetic and electrostatic separation is a good alternative for the recovery of copper from PCBs. However it is necessary to improve the process to obtain higher recoveries.

\subsection{Copper Leaching}

The results of the experimental tests carried out according to the design of experiments are shown in the Table 2.
The first-order model in coded variables, Eq. (2), was obtained. This model presents a lack of fit according to an analysis of variance (P-value $=0.019$ $<0.05)$.

$$
\begin{array}{r}
\text { Extraction }(\%)=41.53+10.94 \mathrm{~A}+ \\
3.75 \mathrm{~B}-5.02 \mathrm{C}
\end{array}
$$

A second order design, more specifically a central composite design was performed to model the curve. For this new experimental design a constant stirring speed was maintained at a value of $400 \mathrm{rpm}$. The experimental design matrix and results are shown in the Table 3.

From an analysis of variance for the experimental results, the second-order model of Eq. (3) was determined. It has a $R^{2}=81.00 \%$ and $R_{a d j}^{2}=$ $77.44 \%$, which is satisfactory to accept the model.

$$
\begin{aligned}
\text { Extraction }(\%) & =-14.331+ \\
13.804 \mathrm{~A} & +8.916 \mathrm{~B}-0.244 \mathrm{~B}^{2}
\end{aligned}
$$

This model fits the data satisfactorily. Better extraction of copper achieved in the experimental region is $95.2 \%$ at a concentration of $2.32 \mathrm{M}$ sulfuric acid and a volume of $18 \mathrm{~mL}$ of hydrogen peroxide.

\subsection{Precipitation}

Copper hydroxide (II) is precipitated from the copper sulphate solution by neutralization by adding sodium hydroxide to the solution as the reaction (4).

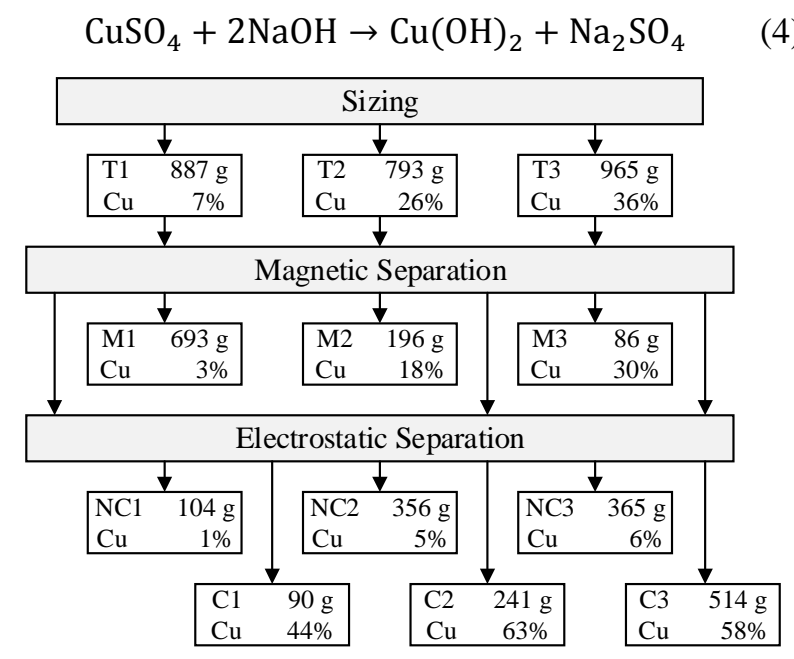

M: magnetic, NC: non conductive, C: conductive

Fig. 2 Results of physical processes. 
Table 3 Central composite design results.

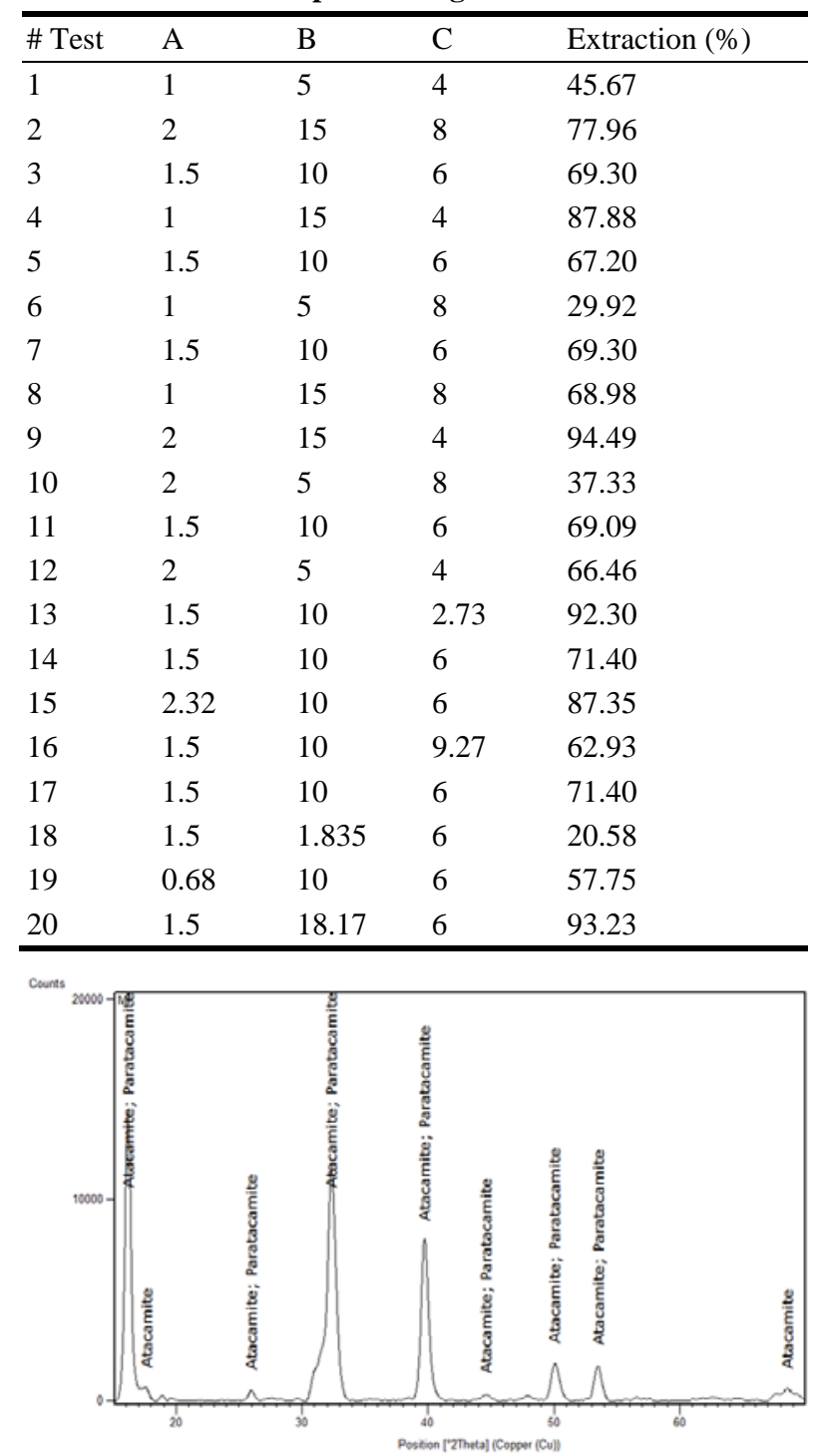

Fig. 3 Diffractogram of the precipitate.

The solution with $\mathrm{Cu}(\mathrm{OH})_{2}$ precipitated was heated to obtain the most stable copper oxide (II) (CuO). The precipitate was filtered and allowed to dry at room temperature. $\mathrm{CuO}$ was dissolved in $1 \mathrm{M}$ hydrochloric acid solution at room temperature in order to obtain the copper chloride (II) according to Eq. (5).

$$
\mathrm{CuO}+2 \mathrm{HCl} \rightarrow \mathrm{CuCl}_{2}+\mathrm{H}_{2} \mathrm{O}
$$

The $\mathrm{CuCl}_{2}$ solution was neutralized by adding sodium hydroxide in order to copper oxychloride obtaining, according to Eq. (6).

$$
4 \mathrm{CuCl}_{2}+6 \mathrm{NaOH} \rightarrow \mathrm{CuCl}_{2} \cdot 3 \mathrm{Cu}(\mathrm{OH})_{2}+6 \mathrm{NaCl}
$$

Finally, filtration and drying were conducted at room temperature to obtain the desired product. An analysis of X-ray diffraction shown in Fig. 3 confirms that indeed copper oxychloride was obtained in the process described above. Atacamite and paratacamite are common form minerals as the copper oxychloride is found in nature [30].

\subsection{Copper Electrowinning}

The copper deposit obtained was subjected to XRF analysis. Average copper content of $99.3 \%$, which is a good percentage and shows the selectivity of the process developed.

\subsection{Copper Leaching with $\mathrm{O}_{2}$ as Oxidant Agent}

A copper leaching test was performed, using the same sample as in the previous process, using $\mathrm{O}_{2}$ as an oxidant. The test was done in a glass beaker of $600 \mathrm{~mL}$ with $200 \mathrm{~mL}$ of $2.32 \mathrm{M}$ sulfuric acid solution and $8 \mathrm{~g}$ of sample on a RCT basic IKAMAG ${ }^{\circledR}$ safety control magnetic stirrer for $24 \mathrm{~h}$. The process was conducted with a stirring speed of $400 \mathrm{rpm}$, room temperature and injection of oxygen $\left(\mathrm{O}_{2}\right)$. It was found that after $18 \mathrm{~h}$ of process a copper extraction of $41.59 \%$ is achieved, and after $24 \mathrm{~h}$, an extraction of $55.44 \%$ is achieved. This process is actually performed slower than using hydrogen peroxide due to the low solubility of gaseous oxygen in the water [31]. The decision to work with one or another process lies in economic and technological aspects.

\section{Conclusions}

The physical processes of magnetic and electrostatic concentration are shown to be effective in the recycling process and represent an excellent alternative since it does not cause pollution. An average recovery of $79 \%$ was obtained.

The copper leaching step yielded a solution rich in copper sulfate suitable for the subsequent extraction of copper. Higher copper extraction was achieved at 95\% in $100 \mathrm{~mL}$ of $2.32 \mathrm{M}$ sulfuric acid solution with $18 \mathrm{~mL}$ of hydrogen peroxide for $60 \mathrm{~min}$. An extraction of 
$55.44 \%$ was also obtained after $24 \mathrm{~h}$ of operation in a $2.32 \mathrm{M}$ sulfuric acid solution with $\mathrm{O}_{2}$ as oxidant.

Unrefined copper with a purity of 99\% by electrowinning can be obtained, this being a technique that does not generate large effluent since the solutions are recirculated to the copper leaching. Copper oxychloride, a byproduct of copper with added value that can be directly used as a fungicide for the control of pests in different crops is also obtained.

It is clear then the applicability of mineral processing techniques to separate metal fractions, ceramics and polymers of PCB and recover copper by extractive metallurgical techniques as an solution to the problem of disposal of WEEE and it is also friendly to the environment, thus contributing to the closing of the cycle of metals and sustainable development.

\section{References}

[1] J. Cui, E. Forssberg, Mechanical recycling of waste electric and electronic equipment: a review, J. Hazard. Mater. 99 (2003) 243-263.

[2] A. Tuncuk, V. Stazi, A. Akcil, E.Y. Yazici, H. Deveci, Aqueous metal recovery techniques from e-scrap: Hydrometallurgy in recycling, Miner. Eng. 25 (2012) 28-37.

[3] A. Das, A. Vidyadhar, S.P. Mehrotra, A novel flowsheet for the recovery of metal values from waste printed circuit boards, Resour. Conserv. Recycl. 53 (2009) 464-469.

[4] B.H. Robinson, E-waste: An assessment of global production and environmental impacts, Sci. Total Environ. 408 (2009) 183-191.

[5] K. Yamamoto, B. Bo, Comparative study on the e-waste recycling systems in Japan and China, J. Environ. Sci. Eng. A. 2 (2013) 427-439.

[6] M. Oteng-Ababio, The legal and the reasonable: exploring the dynamics of e-waste disposal strategies in ghanaian households, J. US-China Public Adm. 9 (2012) 38-52.

[7] A. Luyima, H. Shi, L. Zhang, Leaching studies for metals recovery from waste printed wiring boards, JOM. 63 (2011) 38-41.

[8] H. Yang, J. Liu, J. Yang, Leaching copper from shredded particles of waste printed circuit boards, J. Hazard. Mater. 187 (2011) 393-400.

[9] J.M. Yoo, J. Jeong, K. Yoo, J. Lee, W. Kim, Enrichment of the metallic components from waste printed circuit boards by a mechanical separation process using a stamp mill, Waste Manag. 29 (2009) 1132-1137.

[10] I.O. Ogunniyi, M.K.G. Vermaak, Investigation of froth flotation for beneficiation of printed circuit board comminution fines, Miner. Eng. 22 (2009) 378-385.

[11] H.M. Veit, T.R. Diehl, A.P. Salami, J.S. Rodrigues, A.M. Bernardes, J.A.S. Tenório, Utilization of magnetic and electrostatic separation in the recycling of printed circuit boards scrap, Waste Manag. 25 (2005) 67-74.

[12] H.L. Le, J. Jeong, J.C. Lee, B.D. Pandey, J.M. Yoo, T.H. Huyunh, Hydrometallurgical process for copper recovery from waste printed circuit boards (PCBs), Miner. Process. Extr. Metall. Rev. 32 (2011) 90-104.

[13] Y. Xiang, P. Wu, N. Zhu, T. Zhang, W. Liu, J. Wu, et al., Bioleaching of copper from waste printed circuit boards by bacterial consortium enriched from acid mine drainage, J. Hazard. Mater. 184 (2010) 812-818.

[14] N. Zhu, Y. Xiang, T. Zhang, P. Wu, Z. Dang, P. Li, et al., Bioleaching of metal concentrates of waste printed circuit boards by mixed culture of acidophilic bacteria, J. Hazard. Mater. 192 (2011) 614-619.

[15] S. Ilyas, C. Ruan, H.N. Bhatti, M.A. Ghauri, M.A. Anwar, Column bioleaching of metals from electronic scrap, Hydrometallurgy 101 (2010) 135-140.

[16] G. Liang, Y. Mo, Q. Zhou, Novel strategies of bioleaching metals from printed circuit boards (PCBs ) in mixed cultivation of two acidophiles, Enzyme Microb. Technol. 47 (2010) 322-326.

[17] D. Pant, D. Joshi, M.K. Upreti, R.K. Kotnala, Chemical and biological extraction of metals present in E waste: A hybrid technology, Waste Manag. 32 (2012) 979-990.

[18] P. Quinet, J. Proost, A. Van Lierde, Recovery of precious metals from electronic scrap by hydrometallurgical processing routes, Miner. Metall. Process. 22 (2005) 17-22.

[19] A. Behnamfard, M.M. Salarirad, F. Veglio, Process development for recovery of copper and precious metals from waste printed circuit boards with emphasize on palladium and gold leaching and precipitation., Waste Manag. 33 (2013) 2354-2363.

[20] I. Birloaga, I.D. Michelis, F. Ferella, M. Buzatu, F. Vegliò, Study on the influence of various factors in the hydrometallurgical processing of waste printed circuit boards for copper and gold recovery., Waste Manag. 33 (2013) 935-941.

[21] E. Kim, M. Kim, J. Lee, B.D. Pandey, Selective recovery of gold from waste mobile phone PCBs by hydrometallurgical process, J. Hazard. Mater. 198 (2011) 206-215.

[22] P. Zhu, Z.Y. Fan, J. Liu, Q. Liu, G.R. Qian, M. Zhou, Enhancement of leaching copper by electro-oxidation from metal powders of waste printed circuit board, J. Hazard. Mater. 166 (2009) 746-750.

[23] A. Mecucci, K. Scott, Leaching and electrochemical recovery of copper, lead and tin from scrap printed circuit boards, J. Chem. Technol. Biotechnol. 77 (2002) 449-457.

[24] J.G. Yang, Y.T. Wu, J. Li, Recovery of ultrafine copper 
particles from metal components of waste printed circuit boards, Hydrometallurgy 121-124 (2012) 1-6.

[25] T. Oishi, K. Koyama, S. Alam, M. Tanaka, J.C. Lee, Recovery of high purity copper cathode from printed circuit boards using ammoniacal sulfate or chloride solutions, Hydrometallurgy 89 (2007) 82-88.

[26] E. Kim, M. Kim, J. Lee, J. Jeong, B.D. Pandey, Leaching kinetics of copper from waste printed circuit boards by electro-generated chlorine in $\mathrm{HCl}$ solution, Hydrometallurgy 107 (2011) 124-132.

[27] S. Fogarasi, F. Imre-Lucaci, A. Imre-Lucaci, P. Ilea, Copper recovery and gold enrichment from waste printed circuit boards by mediated electrochemical oxidation, J.
Hazard. Mater. 273 (2014) 215-221.

[28] J. Huang, M. Chen, H. Chen, S. Chen, Q. Sun, Leaching behavior of copper from waste printed circuit boards with Brønsted acidic ionic liquid, Waste Manag. 34 (2014) 483-488.

[29] S. Zhang, E. Forssberg, Mechanical separation-oriented characterization of electronic scrap, Resour. Conserv. Recycl. 21 (1997) 247-269.

[30] F. Habashi, Handbook of Extractive Metallurgy, Wiley-VCH, Weinheim, New York, 1997.

[31] J. Marsden, The Chemistry of Gold Extraction, 2nd, Society for Mining, Metallurgy, and Exploration, Littleton, Colo, 2006. 